\title{
Stability of Tl-Ba-Ca-Cu-O Superconducting Thin Films
}

\author{
M. P. Siegal, D. L. Overmyer, E. L. Venturini, R. R. Padilla, and P. N. Provencio
} Sandia National Laboratories, Albuquerque, NM 87185-1421

ABSTRACT

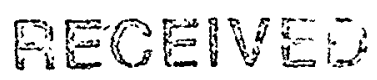

AUG 301989

We report the stability of $\mathrm{TBBa}_{2} \mathrm{CaCu}_{2} \mathrm{O}_{7}(\mathrm{Tl}-1212)$ and $\mathrm{Tl}_{2} \mathrm{Ba}_{2} \mathrm{CaCl}_{2} \mathrm{O}_{8}(\mathrm{Tl}-2212)$ thin films and by inference, the stability of $\mathrm{TlBa}_{2} \mathrm{Ca}_{2} \mathrm{Cu}_{3} \mathrm{O}_{9}$ (Tl-1223) and $\mathrm{Tl}_{2} \mathrm{Ba}_{2} \mathrm{Ca}_{2} \mathrm{Cu}_{3} \mathrm{O}_{10}$ (Tl-2223) thin films, under a variety of conditions. In general, we observe that the stability behavior of the single Tl-O layer materials (Tl-1212 and Tl-1223) are similar and the double Tl-O layer materials (Tl-2212 and T1-2223) are similar. All films are stable with repeated thermal cycling to cryogenic temperatures. Films are also stable in acetone and methanol. Moisture degrades film quality rapidly, especially in the form of vapor. Tl-1212 is more sensitive to vapor than T1-2212. These materials are stable to high temperatures in either $\mathrm{N}_{2}$, similar to vacuum for the cuprates, and $\mathrm{O}_{2}$ ambients. While total degradation of properties (superconducting and structural) occur at the same temperatures for all phases, $600{ }^{\circ} \mathrm{C}$ in $\mathrm{N}_{2}$ and $700{ }^{\circ} \mathrm{C}$ in $\mathrm{O}_{2}$, the onset of degradation occurs at somewhat lower temperatures for Tl-1212 than for Tl-2212 films. In all cases, sample degradation is associated with $\mathrm{Tl}$ depletion from the films. 


\section{DISCLAIMER}

This report was prepared as an account of work sponsored by an agency of the United States Government. Neither the United States Government nor any agency thereof, nor any of their employees, make any warranty, express or implied, or assumes any legal liability or responsibility for the accuracy, completeness, or usefulness of any information, apparatus, product, or process disclosed, or represents that its use would not infringe privately owned rights. Reference herein to any specific commercial product, process, or service by trade name, trademark, manufacturer, or otherwise does not necessarily constitute or imply its endorsement, recommendation, or favoring by the United States Government or any agency thereof. The views and opinions of authors expressed herein do not necessarily state or reflect those of the United States Government or any agency thereof. 


\section{DISCLAIMER}

Portions of this document may be illegible in electronic image products. Images are produced from the best available original document. 


\section{INTRODUCTION}

Thin film high-temperature superconducting (HTS) cuprate quality has improved dramatically in recent years. Epitaxial films grown on perovskite-type single-crystal oxides such as $\mathrm{LaAlO}_{3}$ and $\mathrm{SrTiO}_{3}$ are highly phase-pure, c-axis oriented, and have relatively smooth morphologies. Critical current densities are commonly measured by electrical transport to be $J_{c} \geq 10^{7} \mathrm{~A} / \mathrm{cm}^{2}$ at $5 \mathrm{~K}$ and $\mathrm{J}_{\mathrm{c}}$ $\geq 10^{6} \mathrm{~A} / \mathrm{cm}^{2}$ at $77 \mathrm{~K}$ for films in the $\mathrm{Y}-\mathrm{Ba}-\mathrm{Ca}-\mathrm{Cu}-\mathrm{O}$ [1,2], Tl-Ba-Ca-Cu-O [3-13], and $\mathrm{Hg}-\mathrm{Ba}-\mathrm{Ca}-$ $\mathrm{Cu}-\mathrm{O}$ HTS material systems.[14-16] The best $\mathrm{J}_{\mathrm{c}}$ 's for $\mathrm{Bi}-\mathrm{Sr}-\mathrm{Ca}-\mathrm{Cu}-\mathrm{O}$ films tend to be somewhat lower.[17] The advances in thin film properties are enabling better scientific and more reliable applications studies. An issue that has not been studied extensively is the stability of these improved HTS films in various ambients, and in particular, the Tl-HTS materials.

Structural properties (morphology, crystallographic orientation, and epitaxy) are critical to the resistance of the cuprates to oxygen loss and chemical attack at grain boundaries. This is evident from reports on the adverse effects of moisture to $\mathrm{YBa}_{2} \mathrm{Cu}_{3} \mathrm{O}_{7}$ thin film properties such as critical temperature $\left(T_{c}\right), J_{c}$, and phase purity.[18-33] The superconducting properties of these films were often observed to degrade in ambient conditions simply by being stored in the laboratory. These reports led to a variety of experiments on methods to protect the films from the degradative effects of moisture. One solution involves the low-temperature deposition of amorphous diamondlike carbon (DLC) films to hermetically seal the HTS film surface.[28, 30, 32] An advantage of this approach is that these DLC protective coatings are readily removed by heating the films in an oxygen environment to temperatures near $500^{\circ} \mathrm{C}$. This treatment is ideal for the full oxidation of most HTS materials. Furthermore, the resistance of DLC to most chemicals used for lithographic processing allowed these coatings to also be conveniently used as etch stops.

There has been some work studying the stability of $\mathrm{Hg}-1212$ and $\mathrm{Hg}-1223$ thin resulting from immersion in water [34,35] and in air, acetone, alcohol and thermal cycling.[35] Immersion in all of the liquids above resulted in severe degradation within hours-to-minutes. Severe film 
degradation occurred within minutes upon exposure to humid air. Negligible reaction occurred in dry air for a period of over one year. In contrast, there appears to be only one paper studying the degradation of a Tl-HTS thin film. They found that the superconducting transition temperature, $T_{c}$, and the $\mathrm{X}$-ray diffraction pattern for a Tl-2212 film was stable following immersion in water for 173 days before experiencing degradation.[36]

This paper studies the stability of Tl-Ba-Ca-Cu-O (Tl-HTS) thin films at ambient conditions, in the presence of moisture, and at elevated temperatures in two different ambients important for device processing: $\mathrm{O}_{2}$ and $\mathrm{N}_{2}$. The use of the Tl-HTS system is convenient since all of the known superconducting cuprate crystal structures are available. For this study, we report in detail the evolution in properties of $\mathrm{TlBa}_{2} \mathrm{CaCu}_{2} \mathrm{O}_{7}$ (Tl-1212) and $\mathrm{Tl}_{2} \mathrm{Ba}_{2} \mathrm{CaCu}_{2} \mathrm{O}_{8}$ (Tl-2212) thin films and by inference, the stability of $\mathrm{TIBa}_{2} \mathrm{Ca}_{2} \mathrm{Cu}_{3} \mathrm{O}_{9}$ (Tl-1223) and $\mathrm{Tl}_{2} \mathrm{Ba}_{2} \mathrm{Ca}_{2} \mathrm{Cu}_{3} \mathrm{O}_{10}$ (Tl-2223) thin films. In general, we observe that the stability behavior of the single Tl-O layer materials (Tl-1212 and Tl1223) are similar and the double Tl-O layer materials ( $\mathrm{Tl}-2212$ and $\mathrm{Tl}-2223$ ) are similar.

\section{EXPERIMENT}

The TI-HTS films for this study were grown using two-step methods reported in detail elsewhere.[11, 13] Briefly, amorphous $\mathrm{Ba}-\mathrm{Ca}-\mathrm{Cu}-\mathrm{O}$ precursor films were deposited by off-axis rf sputtering onto both $\mathrm{LaAlO}_{3}(100)$ and $\mathrm{Si}(100)$ substrates. Rutherford backscattering spectrometry (RBS) using $2.0 \mathrm{MeV}{ }^{+} \mathrm{He}^{4}$ ions was used to precisely measure $\mathrm{Ba}: \mathrm{Ca}: \mathrm{Cu}$ cation precursor film stoichiometries on the Si substrates. Only precursors within $\pm 2 \%$ of the desired 0212 or 0223 stoichiometries were used. The second step involved a high-temperature thallination anneal to convert the precursor films into epitaxial superconductors. Tl-1212, Tl-1223, and Tl-2223 films $2000 \AA$ thick were annealed on $\mathrm{LaAlO}_{3}(100)$ substrates by a simplified "crucible" process.[11] Tl2212 films $~ 5500 \AA$ thick were grown by the recently reported "hybrid two-zone furnace/crucible" process.[13] TI-1212 films were thallinated at $825^{\circ} \mathrm{C}$ in 630 Torr $\mathrm{O}_{2}$. Tl-1223 and Tl-2223 films were thallinated at $895-900{ }^{\circ} \mathrm{C}$ in 630 Torr $\mathrm{O}_{2}$. Tl-2212 films were thallinated at $800{ }^{\circ} \mathrm{C}$ in air. 
The annealing times were typically 30 minutes. Following the thallination annealing processes for conversion into superconductors, films were characterized by several methods. Material phase purity and c-axis orientation were determined using $\mathrm{x}$-ray diffraction (XRD) $\theta-2 \theta$ scans from $\mathrm{Cu}$ $K_{\alpha}$ radiation. Scanning electron microscopy (SEM) is used to determine film morphology. Optical microscopy was used to identify degraded film regions. A commercial SQUID magnetometer was used to measure the Meissner transition in a magnetic field of $0.2 \mathrm{mT}$ and to determine the critical current density $\left(\mathrm{J}_{\mathrm{c}}\right)$ at $7 \mathrm{~K}$ in a low field applied perpendicular to the plane of the film.[37]

Films were carefully selected based upon structural and superconducting measurements for use in this study. Such selection is important to provide confidence in the stability determinations. The goal is to minimize the effects of secondary material phases and large-angle grain boundaries so that the measurements performed are as intrinsic as possible to a given Tl-HTS crystal structure. Fig. 1 shows the typical XRD patterns obtained from each type of TI-HTS film. Note that each T1HTS material used is single-phased and highly c-axis oriented. The onset Meissner transition temperatures are $\sim 95,103,108$, and $115 \mathrm{~K}$ for these Tl-1212, Tl-2212, Tl-1223, and Tl-2223 films, respectively. $\mathrm{J}_{\mathrm{c}}(7 \mathrm{~K})$ is $\sim 1( \pm 20 \%) \times 10^{7} \mathrm{~A} / \mathrm{cm}^{2}$ for all films used. SEM shows the underlying morphology of these films to be relatively smooth. Off-composition precipitates occur on the surface. This is shown in fig. 2 for Tl-1212 and Tl-1223 films. We note that the morphology of Tl-2212 films is similar to those of Tl-1212 films, and the morphology of Tl-2223 films is similar to that of $\mathrm{Tl}-1223$ films.

A motivation for this experiment was our general observation of Tl-HTS film properties over time while stored in the laboratory without any precautions. We found that both Tl-1212 and Tl1223 films degrade over a period of several months to a year. No such degradation was observed from the double $\mathrm{Tl}-\mathrm{O}$ layer films, $\mathrm{Tl}-2212$ and $\mathrm{Tl}-2223$. The degradation in the single Tl-O layer films was observed in several different ways. Most obvious was the change in coloration of the 
films, which became optically transparent with degradation. XRD found a severe loss in the intensity of the c-axis peaks seen in fig. 1. The onset of the Meissner transition is depressed by tens of degrees and greatly broadened such that a full transition is not observed for films beyond a certain level of degradation. $\mathrm{J}_{\mathrm{c}}(7 \mathrm{~K})$ values fall over three orders of magnitude into the noise level of the SQUID magnetometer.

In an effort to elucidate upon the nature of this sample degradation at ambient laboratory conditions (atmospheric room temperature), we performed a variety of stability studies on Tl-1212 and Tl-2212 films. These two phases were chosen for more detailed study since they are easier to produce in high-quality, and together, they appear to be representative of the chemistry of single and double TI-O layer materials, respectively. Simple room-temperature tests include immersion into distilled, deionized (DI) water, methanol, and acetone, as well as passing oxygen containing water vapor- at a low flow rate over the film surfaces. To further study the stability of these films under a variety of possible device processing conditions, films were treated to increasingly higher temperatures in oxygen and nitrogen ambients. To eliminate sample-to-sample variations, a given sample is used throughout an entire experiment until its degradation is complete. These experiments were repeated on several samples and the results presented are representative. Great care is taken while handling the samples between the various processing and measurement steps of the experiments so as not to accidentally scratch the films. Such mechanical damage results in discontinuous behavior in the critical current measurements made as a function of processing temperature or time. Scratches also appear to be ideal places on a sample for degradation to nucleate. Following the completion of a multiple-step processing experiment, fresh thin film samples were processed at particular conditions to ascertain the reproducibility of the stability results. For temperature experiments in nitrogen, Tl-1212 films were occasionally annealed in oxygen at $400{ }^{\circ} \mathrm{C}$ to determine whether or not the effects observed result from oxygen loss or structural degradation. All Tl-2212 nitrogen anneals were followed with an oxygen anneal. 
Another mechanism for mechanical damage to occur is from differences in thermal expansion between a Tl-HTS film and its $\mathrm{LaAlO}_{3}(100)$ single crystal substrate. Microcracking due to thermal cycling between room temperature and the $7 \mathrm{~K}$ temperature of our $\mathrm{J}_{\mathrm{c}}$ measurements would definitely reduce $J_{c}$ and potentially cause misinterpretation of the results. To test this possibility, we cycled both Tl-1212 (16 times) and Tl-2212 (18 times) between these two temperatures and found no changes in the magnetization measurement of critical current density from either sample.

\section{RESULTS and DISCUSSION}

\section{A. Room-temperature stability}

Tl-HTS films are stable when stored in dry ambients in the laboratory for long periods of time (greater than one year). We have tested storage in both a flowing oxygen box containing drierite and in an argon glove box without finding any differences in measured film properties $\left(\mathrm{T}_{\mathfrak{c}}\right.$, $J_{c}(7 K)$, surface appearance, and XRD pattern and intensity). The degradation of Tl-1212 films discussed above in an unprotected ambient in the laboratory does not occur immediately, but rather is the result of a nucleation reaction similar to corrosion. The onset times of these processes seem to be on the order of weeks to months depending upon the atmospheric temperature and humidity conditions. Once degradation of a Tl-1212 film is observed, normally by slight discoloration of the film, which corresponds to a slight decrease in $\mathrm{J}_{c}(7 \mathrm{~K})$ without an obvious change in XRD intensity, the decline in properties occurs very rapidly over the next few days. The films become more transparent, the XRD pattern weakens, and $\mathrm{J}_{c}(7 \mathrm{~K})$ becomes negligible. These results are not reversible with an oxygen anneal; i.e. there is a permanent loss in the superconducting cuprate crystal structure that cannot be recovered while maintaining the smooth morphology required for any scientific or device application.

A previous study by Yan and coworkers found that the $T_{c}$ of $\mathrm{Tl}-2212$ films are stable up to 173 days when immersed in DI water.[36] $\mathrm{T}_{c}$ was determined by depositing metal contacts onto the films and performing resistance versus temperature transport measurements. Unfortunately, 
critical current density measurements were not meaningful in their experiment due to their observed corrosion of the metal contact pads in the DI water. The quality of the HTS-metal contacts are critical for reliable $J_{c}$ measurements. By performing our contactless measurements with a SQUID magnetometer, we can observe small changes in $J_{c}$ that are very sensitive to minute structural alterations of the samples. Immersion of both Tl-1212 and Tl-2212 films for only 30 minutes in DI water results in decreases of $J_{c}(7 \mathrm{~K})$ of $10-15 \%$. No such degradation of either superconducting phase is observed following 30 minute immersion in either methanol or acetone. The relevance of these simple chemical immersion experiments are obvious for any form of sample processing for a variety of purposes, such as the chemical-mechanical polishing of films for transmission electron microscopy (TEM) sample preparation, or the chemical cleaning and etching performed on films for device processing.

Indeed, we had often experienced sample degradation while preparing TEM samples using DI water as a lubricating coolant. The severity of this degradation was often far worse (total loss of the ability to image any crystalline regions) than the immersion experiments would suggest. The polishing process used also generates localized water vapor. We tested the stability of Tl-HTS films under conditions of a mild flow of wet oxygen. Samples were placed in a quartz tube. Oxygen bubbled through DI water was passed through the tube. Tl-1212 films became completely transparent in less than 5 minutes. This visual change was accompanied by a complete loss of the $\mathrm{XRD}$ pattern, shown on a log scale in fig. 3 , and any measurement of superconductivity. Note that $\mathrm{XRD}$ does not detect the presence of any new material phase formation, simply a several orders of magnitude decrease in the signal intensity of the Tl-1212 diffraction peaks. The insensitivity to the formation of new phases only suggests that the grain sizes of such new phases are very small, and perhaps unaligned.

The nucleation and spread of this corrosion-type degradation was much slower, although still measurable in Tl-2212 films. Figure 4 shows the evolution of the spread of such corrosion on a 
Tl-2212 film after 2 and 4 hours of flowing wet oxygen at room temperature. These transmission optical micrographs show that the degradation appears to nucleate at damaged regions, such as the cleaved edges of the sample. Fig. 4(b) shows that this degradation can also nucleate at other locations within the film; note the lower left portion of the image. It is not known if this is a site of random nucleation, a damage site in the film resulting from mechanical handling, or a site of a defect in the as-grown film such as a pinhole, larger-than-normal grain boundary, or simply a spot with a non-Tl-2212 oxide particulate, or even a dust particle. In figure 5 we plot the critical current density measurement normalized to its as-grown value as a function of time exposure to the flowing wet oxygen gas. After 19 hours, the sample has lost $\sim 80 \%$ of its current-carrying ability, and appears to be mostly degraded from optical microscopy as well. The XRD signal intensity is greatly reduced. Annealing the sample in dry oxygen at $400{ }^{\circ} \mathrm{C}$ did not recover the $\mathrm{Tl}-2212$ phase or its as-grown superconducting properties.

These results show that the presence of water is harmful to the stability of Tl-HTS thin films. The effects of water on Tl-1212 are more severe than on T1-2212. By inference to observations from Tl-1223 and Tl-2223 films, we believe that the measured moisture degradation properties are general to single Tl-O and double Tl-O layer superconducting crystal structures. Water in vapor form is significantly worse, perhaps due to its superior ability to come into physical contact with a film surface. By storing Tl-HTS films in dry ambients, no degradation of properties is observed for periods approaching one year. Neither short time exposures to acetone nor methanol appear to cause any measurable change in properties of Tl-1212 or Tl-2212 films, allowing the use of these standard cleanroom chemicals for sample processing. These results are consistent with those found for $\mathrm{YBaCuO}$ and $\mathrm{Hg}$-HTS films.[18-35] The mechanism for degradation is likely the ability of both $\mathrm{Ba}$ and $\mathrm{Ca}$ to easily form hydroxides.[35] 


\section{B . High-temperature stability in oxygen and nitrogen ambients}

The long-term stability of Tl-HTS thin film properties in dry ambient conditions is not addressed in the experiments described above. To accelerate the degradation of film properties, experiments were performed at elevated temperatures in both oxygen and nitrogen ambients. Films were measured by $\mathrm{XRD}$ and for $\mathrm{J}_{\mathrm{c}}(7 \mathrm{~K})$ after growth and then after successively higher temperature one hour furnace anneals. On occasion, the sequence of $\mathrm{N}_{2}$ anneals is interrupted with a $400{ }^{\circ} \mathrm{C} \mathrm{O}_{2}$ anneal to determine if the degradation in $\mathrm{J}_{\mathrm{c}}(7 \mathrm{~K})$ is related primarily to oxygen-loss or to irreversible structure changes.

\section{Oxygen annealing}

The critical current density measured at $7 \mathrm{~K}$ from Tl-1212 and Tl-2212 epitaxial films appears to be stable in oxygen to temperatures greater than 500 and $650{ }^{\circ} \mathrm{C}$, shown in figures $6(\mathrm{a})$ and 6 (b), respectively. These results attest to the robustness of these Tl-HTS materials in hightemperature oxygen ambients. The XRD pattern and peak intensities remain unchanged for these films over this range of annealing. For $\mathrm{Tl}-1212, \mathrm{~J}_{\mathrm{c}}(7 \mathrm{~K})$ begins to decrease at temperatures above $500^{\circ} \mathrm{C}$ over a $200^{\circ}$ range, becoming negligible by $700{ }^{\circ} \mathrm{C}$. $\mathrm{J}_{\mathrm{c}}(7 \mathrm{~K})$ for $\mathrm{Tl}-2212$ films does not begin to decrease until temperatures above $650{ }^{\circ} \mathrm{C}$, but falls very quickly over a $50^{\circ}$ range to negligible values also by $700^{\circ} \mathrm{C}$.

The XRD peak intensities decrease at temperatures corresponding to the decrease in $\mathrm{J}_{\mathrm{c}}(7 \mathrm{~K})$ for both Tl-1212 and Tl-2212 films. This is shown in figure 8 for a Tl-2212 film annealed in $\mathrm{O}_{2}$ successively at 685,690 and $695^{\circ} \mathrm{C}$. By $700{ }^{\circ} \mathrm{C}$, there are no discernable Tl-2212 XRD peaks. The degradation of the XRD pattern for Tl-1212 is similar to that for Tl-2212 and is discussed in an earlier publication.[38] The decrease in XRD peak intensities is associated with an increase in structural disorder. This disorder can be in the form of smaller grain sizes and/or the creation of point defects within the crystalline grains. The creation of such disorder is consistent with the sublimation of $\mathrm{Tl}-\mathrm{O}$ from the films during the annealing. Indeed, EDX finds a significant loss of 
$\mathrm{Tl}$ in films annealed at $700^{\circ} \mathrm{C}$ in $\mathrm{O}_{2}$. EDX averaged over a large area $\left(500 \mu \mathrm{m}^{2}\right)$ finds no change in the Tl-2212 film Ba:Ca:Cu ratio of 2:1:2 with annealing, however, the Tl-content decreases substantially from $\sim 2.0$ to 0.4 . We associate the initial depletion of Tl-O from Tl-1212 and Tl2212 films with the creation of defects leading to enhanced flux pinning.[38-41]

\section{Nitrogen annealing}

Figure 8 shows the behavior of $\mathrm{J}_{\mathrm{c}}(7 \mathrm{~K})$ of $\mathrm{Tl}-1212$ films as a function of annealing in $\mathrm{N}_{2}$ ambients at increasing temperatures. The $\mathrm{J}_{\mathrm{c}}(7 \mathrm{~K})$ of $\mathrm{Tl}-1212$ decreases rapidly at annealing temperatures above $200{ }^{\circ} \mathrm{C}$ and becomes negligible by $275^{\circ} \mathrm{C}$. Similar behavior is observed for Tl-2212 films, with $\mathrm{J}_{c}(7 \mathrm{~K})$ becoming negligible by $325^{\circ} \mathrm{C}$. However, the appearance of these films is still quite dark and uniform. Furthermore, the XRD spectra following these anneals remains unchanged in peak positions and intensities. To determine whether the sharp decreases in $J_{c}(7 \mathrm{~K})$ were simply the result of reversible oxygen loss in these reducing ambients, we then annealed both the Tl-1212 and Tl-2212 films in $\mathrm{O}_{2}$ at $400^{\circ} \mathrm{C}$. The result was a complete recovery of $J_{c}(7 \mathrm{~K})$ in each film.

Anneals in $\mathrm{N}_{2}$ at increasingly higher temperatures again produce a decrease in $\mathrm{J}_{\mathrm{c}}(7 \mathrm{~K}) . \quad \mathrm{O}_{2}$ anneals were performed following those $\mathrm{N}_{2}$ temperature anneals that caused a decrease in magnetization $\mathrm{J}_{\mathrm{c}}(7 \mathrm{~K})$ measurements to noise levels of the SQUID magnetometer. These decreases in $\mathrm{J}_{\mathrm{c}}(7 \mathrm{~K})$ occur over smaller ranges of temperature with increasing annealing temperature. For both TI-HTS phases, this behavior changes abruptly at annealing temperatures above $400{ }^{\circ} \mathrm{C}$. Anneals above this temperature do not reduce $J_{c}(7 \mathrm{~K})$ values to zero. These anneals were not followed with any oxygen anneals. For Tl-1212 films, $J_{c}(7 \mathrm{~K})$ decreases slowly with increasing nitrogen annealing temperature to $550^{\circ} \mathrm{C}$. Above this temperature, $\mathrm{J}_{\mathrm{c}}(7 \mathrm{~K})$ falls rapidly to zero.

Clearly the decreases in $J_{c}(7 \mathrm{~K})$ at temperatures well below the sample degradation temperature of $600{ }^{\circ} \mathrm{C}$ for anneals performed in $\mathrm{N}_{2}$ are the result of reversible changes in the 


\section{Stability of Tl-Ba-Ca-Cu-O Superconducting Thin Films}

oxygen concentration of the films, not irreversible changes due to Tl depletion. To demonstrate this, we repeated the stability experiment for Tl-2212 films. This time, each $\mathrm{N}_{2}$ anneal was followed with a $400{ }^{\circ} \mathrm{C}$ anneal in $\mathrm{O}_{2}$. The results are shown in figure $9 . \mathrm{J}_{c}(7 \mathrm{~K})$ remains essentially unchanged for double anneals up to $585^{\circ} \mathrm{C}$, and then falls off very rapidly to zero by $600{ }^{\circ} \mathrm{C}$. These $\mathrm{N}_{2}$ annealing results are consistent with those obtained for $\mathrm{O}_{2}$ annealing. Superconductivity becomes negligible in both Tl-1212 and Tl-2212 films at the same temperature: $600{ }^{\circ} \mathrm{C}$ in $\mathrm{N}_{2}$ and $700{ }^{\circ} \mathrm{C}$ in $\mathrm{O}_{2}$. Degradation associated with $\mathrm{Tl}-\mathrm{O}$ loss from the films, however, begins at lower temperatures in each ambient for $\mathrm{Tl}-1212$ than for $\mathrm{Tl}-2212$. In all cases, degradation resulting from $\mathrm{Tl}$ depletion is accompanied by a change in the appearance of the films from dark and uniform to transparent and splotchy. These changes are also confirmed with the weakening of the XRD peak intensities. It should be noted that the low temperature annealing results are different from those obtained in Tl-1223 single crystals, where annealing for at least 200 hours at $400{ }^{\circ} \mathrm{C}$ in either flowing $\mathrm{O}_{2}$ or $\mathrm{N}_{2}$ result in only minor changes in $\mathrm{T}_{\mathrm{c}}$. However, the results are not inconsistent given the presence of grain boundaries in the films which facilitate oxygen diffusion.[12, 42]

\section{SUMMARY}

We studied the stability of Tl-HTS films under a variety of conditions. In general, we observe that the behavior of single Tl-O layer materials (Tl-1212 and Tl-1223) are similar and that the behavior of the double Tl-O layer materials (Tl-2212 and Tl-2223) are similar. None of the materials are affected by immersion in either methanol or acetone, or by repetitive thermal cycling between 7 and $300 \mathrm{~K}$. These results are promising for the use of standard post-processing chemicals and actual applications. All Tl-HTS materials are sensitive to moisture, especially in the form of vapor, similar to the behavior of the other cuprate superconductors. It should be noted that $\mathrm{Tl}-2212$ is significantly more stable under these conditions than Tl-1212, which may be important for material selection in certain applications. These materials can be easily protected in storage using dry ambient conditions. Tl-2212 films also are slightly more stable than Tl-1212 films at 
elevated temperatures in either oxygen or nitrogen ambients. However, the total degradation of both structural and superconducting properties occurs at the same temperatures in $\mathrm{N}_{2}\left(600^{\circ} \mathrm{C}\right)$ and in $\mathrm{O}_{2}\left(700^{\circ} \mathrm{C}\right)$, resulting from the catastrophic depletion of $\mathrm{Tl}-\mathrm{O}$ from the films. In conclusion, the thermal stability of Tl-HTS materials extends above $500{ }^{\circ} \mathrm{C}$ in any oxygen ambient condition $(0$ to $100 \%$ ), allowing the materials to easily survive any foreseeable type of post-processing condition necessary for sample preparation or device fabrication.

\section{Acknowledgment}

Sandia is a multiprogram laboratory operated by Sandia Corporation, a Lockheed Martin Company, for the U.S. DOE under Contract DE-AC04-94AL85000. This work was supported by the DOE Office of Basic Energy Sciences, Division of Material Science. 


\section{REFERENCES}

1. M. P. Siegal, J. M. Phillips, R. B. van Dover, T. H. Tiefel, and J. H. Marshall, J. Appl. Phys. 68, 6353 (1990).

2. A. Inam, X. D. Wu', L. Nazar, M. S. Hedge, C. T. Rogers, T. Venkatesan, R. W. Simon, K. Daly, H. Padamsee, J. Kirchgessner, D. Moffat, D. Rubin, Q. S. Shu, K. Kalokitis, A. Fathy, V. Pendrick, R. Brown, B. Brycki, E. Belohoubek, L, Drabeck, G. Gruner, R. Hammond, F. Gamble, B. M. Lairson, and J. C. Bravman, Appl. Phys. Lett. 56, 1178 (1990).

3. R. B. Hammond, G. V. Negrete, L. C. Bourne, D. D. Strother, A. H. Cardona, and M. M. Eddy, Appl. Phys. Lett. 57, 825 (1990).

4. W. Y. Lee, S. M. Garrison, M. Kawasaki, E. L. Venturini, B. T. Ahn, R. Beyers, J. Salem, R. Sayoy, and J. Vazquez, Appl. Phys. Lett. 60, 772 (1992).

5. S. L. Yan, L. Fang, Q. X. Song, J. Yan, Y. P. Zhu, J. H. Chen, and S. B. Zhang, Appl. Phys. Lett. 63, 1845 (1993).

6. Z. F. Ren, C. A. Wang, and J. H. Wang; Appl. Phys. Lett. 65, 237 (1994).

7. J. Y. Juang, J. H. Horng, H. C. Lin, S. J. Wang, C. M. Fu, K. H. Wu, T. M. Uen, and Y. S. Gou, IEEE Trans. Appl. Supercond. 5, 1689 (1995).

8. M. P. Siegal, E. L. Venturini, P. P. Newcomer, D. L. Overmyer, F. Dominguez, and R. Dunn, J. Appl. Phys. 78, 7186 (1995).

9. M. P. Siegal, N. Missert, E. L. Venturini, P. P. Newcomer, F. Dominguez, and R. Dunn, IEEE Trans. Appl. Supercond. 5, 1343 (1995).

10. W. L. Holstein and L. A. Parisi, J. Mater. Res. 11, 1349 (1996).

11. M. P. Siegal, D. L. Overmyer, E. L. Venturini, P. P. Newcomer, R. Dunn, F. Dominguez, R. R. Padilla, and S. S.,Sokolowski, IEEE Trans. Appl. Supercond. 7, 1881 (1997).

12. M. P. Siegal, E. L. Venturini, B. Morosin, and T. L. Aselage, J. Mater. Res. 12, 2825 (1997). 
13. M. P. Siegal, D. L. Overmyer, E. L. Venturini, F. Dominguez, and R. R. Padilla, J. Mater. Res. 13, 3349 (1998).

14. L. Krusinelbaum, C. C. Tsuei, and A. Gupta, Nature, 373, 679 (1995).

15. S. H. Yun and J. Z. Wu, Appl. Phys. Lett. 68, 862 (1996).

16. S. L. Yan, Y. Y. Xie, J. Z. Wu, T. Aytug, A. A. Gapud, B. W. Kang, L. Fang, M. He, S. C. Tidrow, K. W. Kircherner, J. R. Liu, and W. K. Chu, Appl. Phys. Lett. 73, 2989 (1998).

17. H. Yamasaki, K. Endo, Y. Nakagawa, M. Umeda, S. Kosaka, S. Misawa, S. Yoshida, and K. Kajimura, J. Appl. Phys. 72, 2951 (1992).

18. G. N. A. Vanveen, T. S. Baller, J. W. C. Devries, and . M. Stollman, Physica C 152, 267 (1988).

19. C. A. Chang, Appl. Phys. Lett. 53, 1113 (1988).

20. C. A. Chang and J. A. Tsai, Appl. Phys. Lett. 53, 1976 (1988).

21. D. K. Pham, R. P. Zhao, P. E. Fielding, S. Myhra and P. S. Turner, J. Mater. Res. 6, 1148 (1991).

22. T. H. Buyuklimanlith and J. H. Simmons, Phys. Rev. B 44, 727 (1991).

23. T. Ohara, K. Sakuta, M. Kamishiro, and T. Kobayashi, Jap. J. Appl. Phys. 30, L2085 (1991).

24. S. Kale, M. Swaminathan, and S. B. Ogale, Thin Solid Films 206, 161 (1991).

25. O. Muller, J. Schubert, W. Zander, and B. Stritzker, Physica C 191, 103 (1992).

26. A. A. Jussain and M. Sayer, Vacuum 43, 1195 (1992).

27. R. P. Zhao, C. A. Davis, M. J. Goringe, P. C. Healy, S. Mygra and P. S. Turner, Appl. Surf. Sci. 65-66, 198 (1993).

28. L. Ganapathi, S. Giles, and R. Rao, Appl. Phys. Lett. 63, 993 (1993).

29. S. E. Russek, S. C. Sanders, A. Roshko, and J. W. Ekin, Appl. Phys. Lett. 64, 3649 (1994). 
30. J. Dreyfuss Tatum, J. W. H. Tsai, M. Chopra, and S.-W. Chan, J. Appl. Phys. 77, 6370 (1995).

31. A. Mogro Campero, K. W. Paik, and L. G. Turner, J. Supercond. 8, 95 (1995).

32. A. L. Karuzskii, N. N. Melnik, V. N. Murzin, V. S. Nozdrin, A. V. Perestoronin, N. A. Volchkkov, and B. G. Zhurkin, Appl. Surf. Sci. 92, 457 (1996).

33. J. P. Zhoa, R. K. Lo, S. M. Savoy, M. Arendt, J. Armstrong, D. Y. Yang, J. Talvacchio, and J. T. McDevitt, Physica C 273, 223 (1997).

34. S. H. Yun and U. O. Karlsson, J. Appl. Phys. 82, 6348 (1997).

35. T. Aytug, B. W. Kang, S. L. Yan, Y. Y. Xie, and J. Z. Wu, Physica C, 307, 117 (1998).

36. S. L. Yan, L. Fang, M. S. Si, J. Wang, H. L. Cao, Z. X. Song, X. D. Zhou, and J. M. Hao, Solid St. Comm. 98, 723 (1996).

37. E. M. Gyorgy, R. B. van Dover, K A. Jackson, L. F. Schneemeyer, and J. V. Waszczak, Appl. Phys. Lett. 55, 283 (1989).

38. M. P. Siegal, E. L. Venturini, P. P. Newcomer, B. Morosin, D. L. Overmyer, F, Dominguez, and R. Dunn, Appl. Phys. Lett. 67, 3966 (1995).

39. E. L. Venturini, P. P. Newcomer, M. P. Siegal, and D. L. Overmyer, IEEE Trans. Appl. Supercond. 7, 1592 (1997).

40. P. P. Newcomer, M. P. Siegal, E. L. Venturini, B. Morosin, and D. L. Overmyer, IEEE Trans. Appl. Supercond. 7, 1887 (1997).

41. M. P. Siegal, D. L. Overmyer, E. L. Venturini, R. R. Padilla, and P. N. Provencio, IEEE Trans. Appl. Supercond. (in press)

42. B. Morosin, E.L. Venturini, and D.S. Ginley, Physica C, 183, 90 (1991). 


\section{Figure Captions}

1. XRD patterns from c-axis oriented, phase pure Tl-HTS films on $\mathrm{LaAlO}_{3}(100)$; a) Tl-1212, b) Tl-2212, c) Tl-1223, and d) Tl-2223.

2. Morphology of a) Tl-1212 and b) Tl-1223 films from SEM.

3. XRD of Tl-1212 films as-grown (lower) and following 5 minutes in flowing wet $\mathrm{O}_{2}$ (upper). Note that the intensities are plotted on a logarithmic scale.

4. Transmission optical micrographs showing the spread of corrosion in a T1-2212 film after (a) 2 hours and (b) 4 hours in flowing wet $\mathrm{O}_{2}$ at room temperature.

5. $\mathrm{J}_{\mathrm{c}}(5 \mathrm{~K})$ vs. time exposure to flowing wet $\mathrm{O}_{2}$ at room temperature for a Tl-2212 film.

6. $\quad \mathrm{J}_{\mathrm{c}}(7 \mathrm{~K})$ vs. $\mathrm{O}_{2}$ annealing temperature for (a) Tl-1212 and (b) Tl-2212 films.

7. XRD patterns for $\mathrm{Tl}-2212$ films at $\mathrm{O}_{2}$ annealing temperatures in the degradation range.

8. $\mathrm{J}_{\mathrm{c}}(7 \mathrm{~K})$ vs. $\mathrm{N}_{2}$ annealing temperature for $\mathrm{Tl}-1212$ films. Whenever the $\mathrm{J}_{\mathrm{c}}(7 \mathrm{~K})$ became negligible, the film was annealed at $400{ }^{\circ} \mathrm{C}$ in $\mathrm{O}_{2}$ for one hour.

9. $\mathrm{J}_{\mathrm{c}}(7 \mathrm{~K})$ vs. $\mathrm{N}_{2}$ annealing temperature for Tl-2212 films. Each $\mathrm{N}_{2}$ anneal was followed by a $400^{\circ} \mathrm{C}$ anneal in $\mathrm{O}_{2}$ for one hour. 

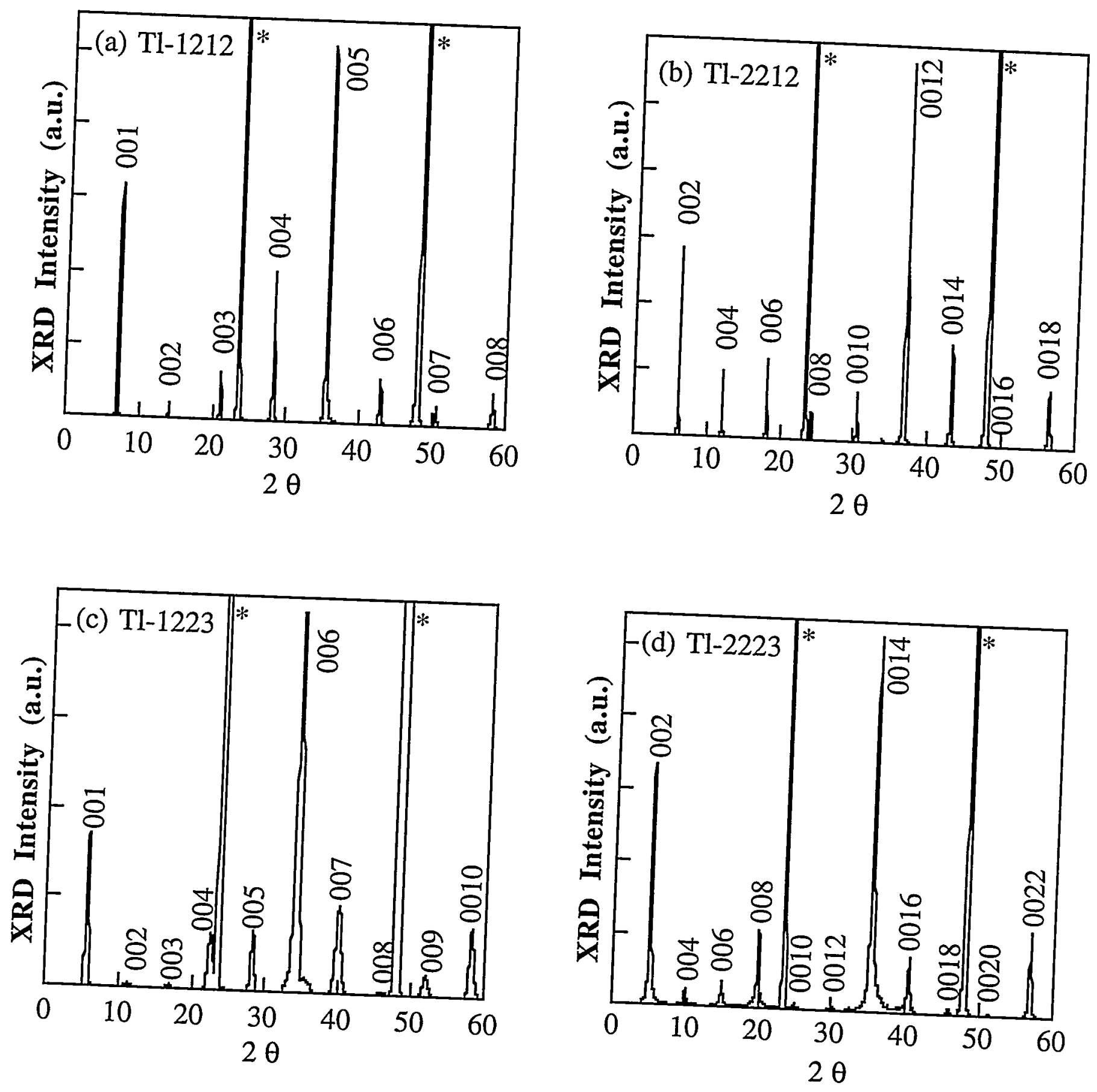

Fig. 1 

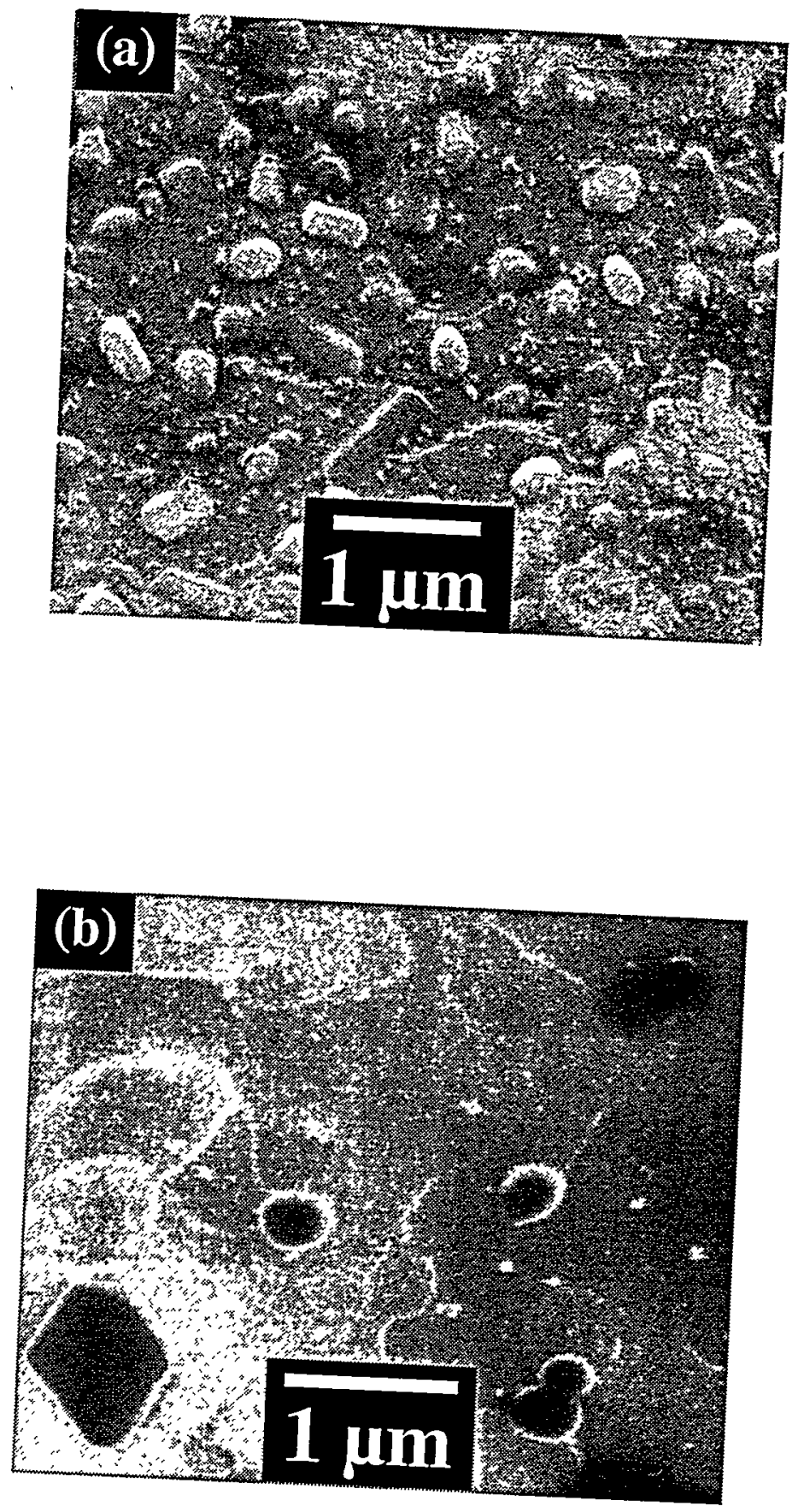

Fig. 2 


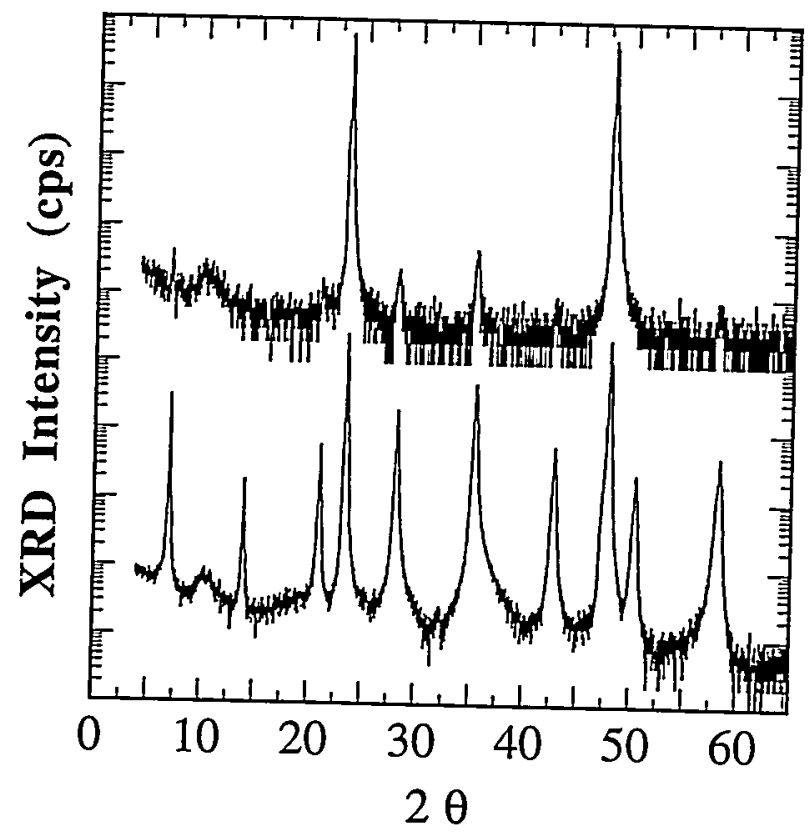

Fis. 3 

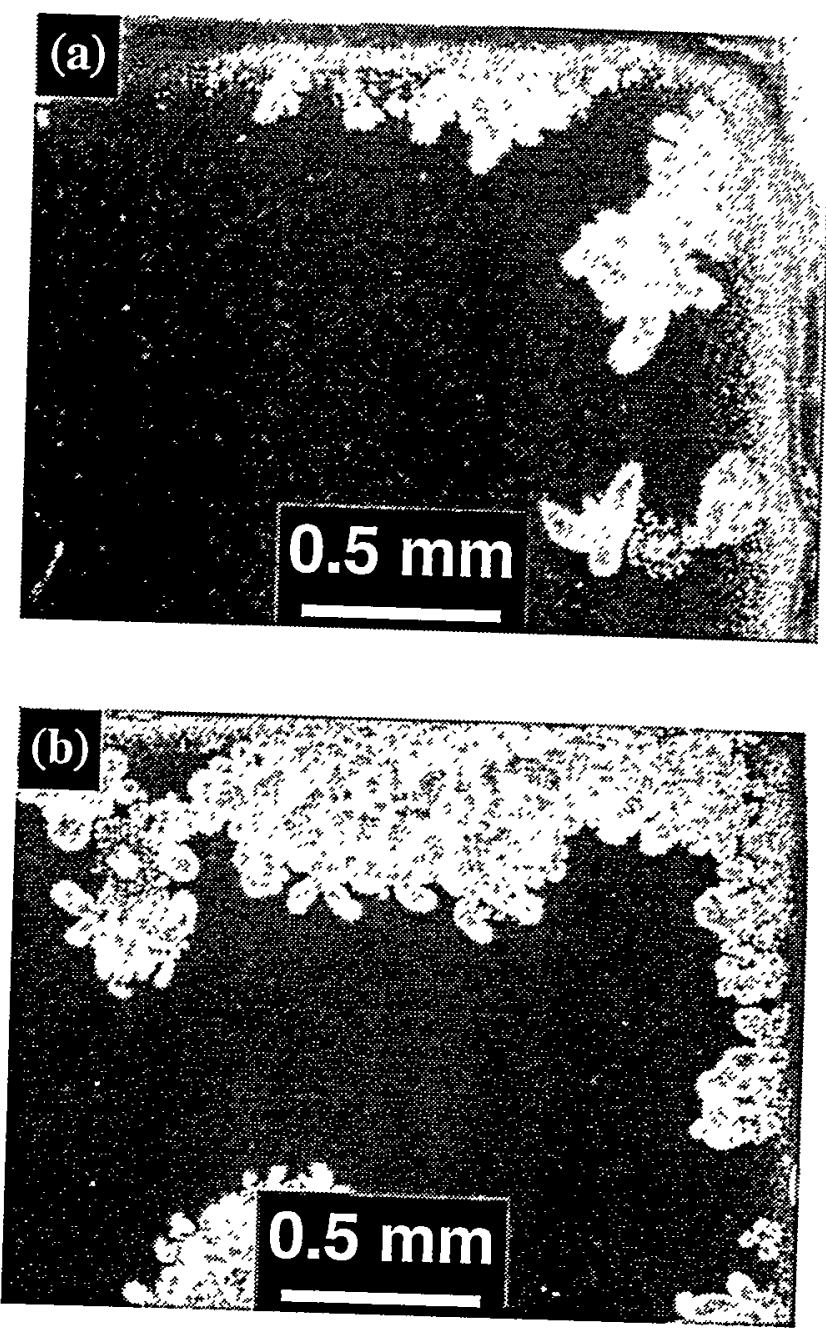

Fis. 4 


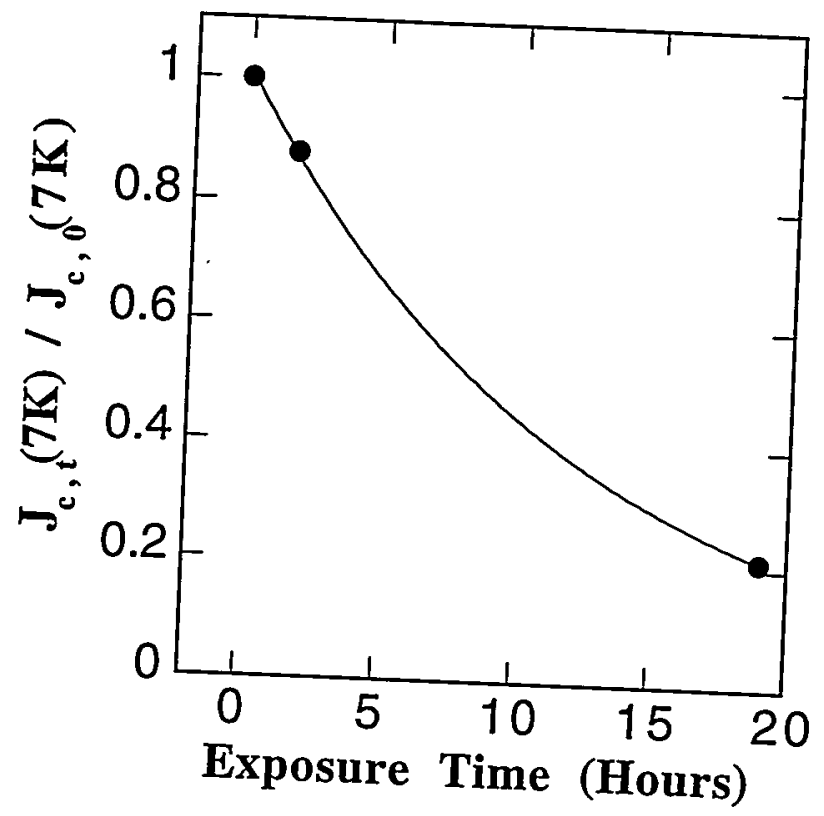

Fig. 5 


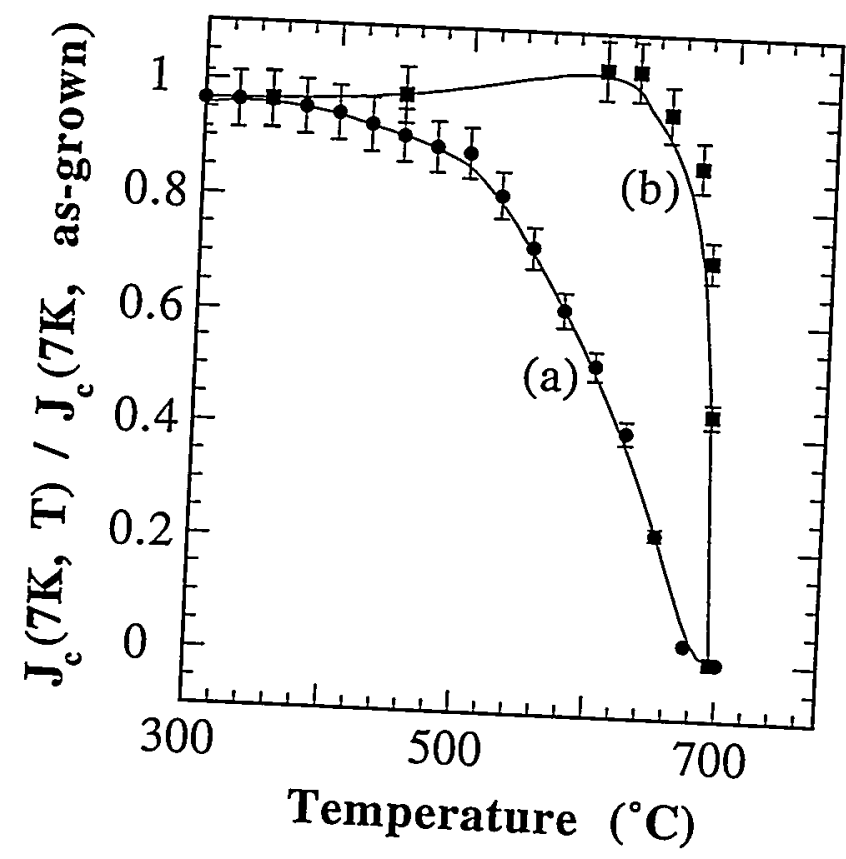

Fig. 6 


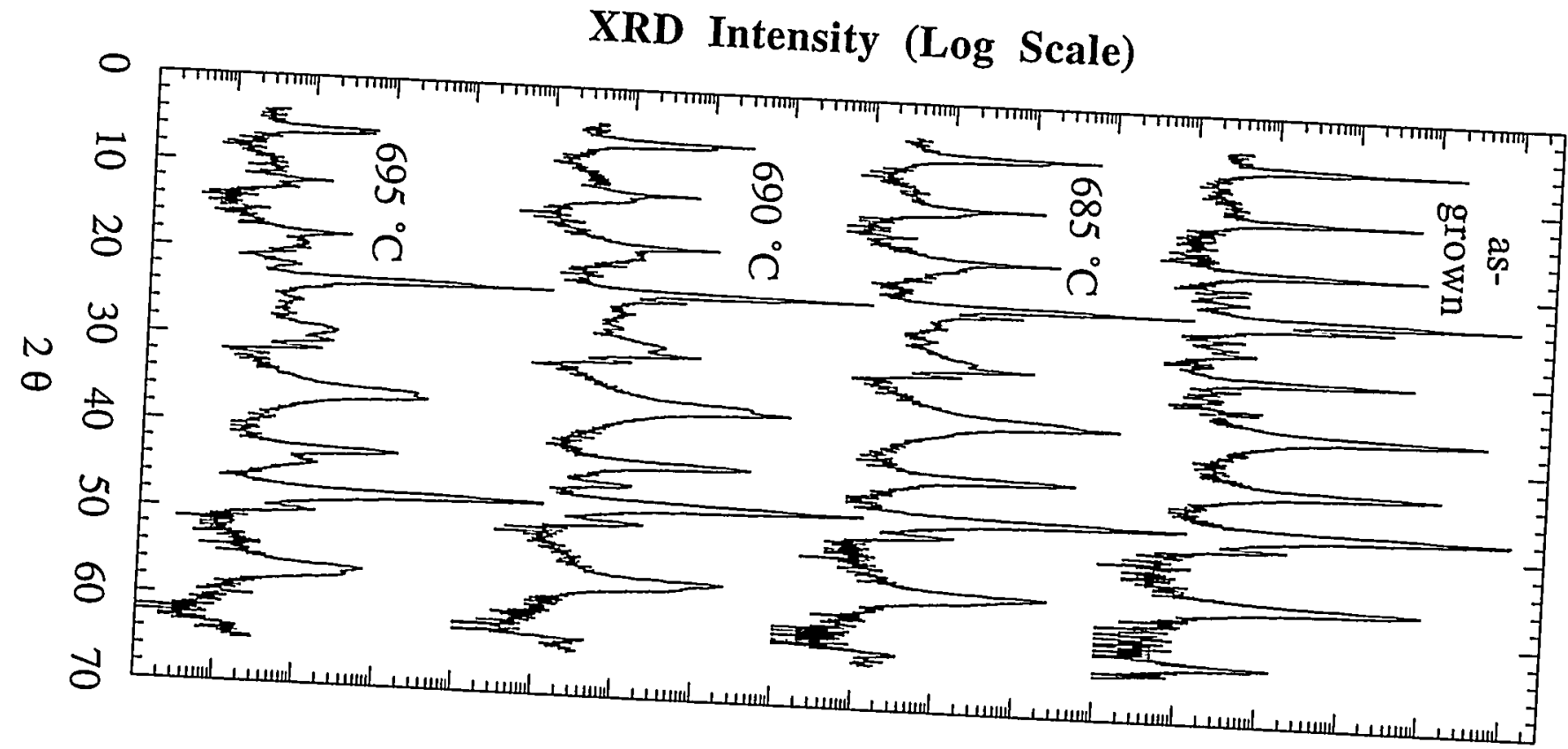




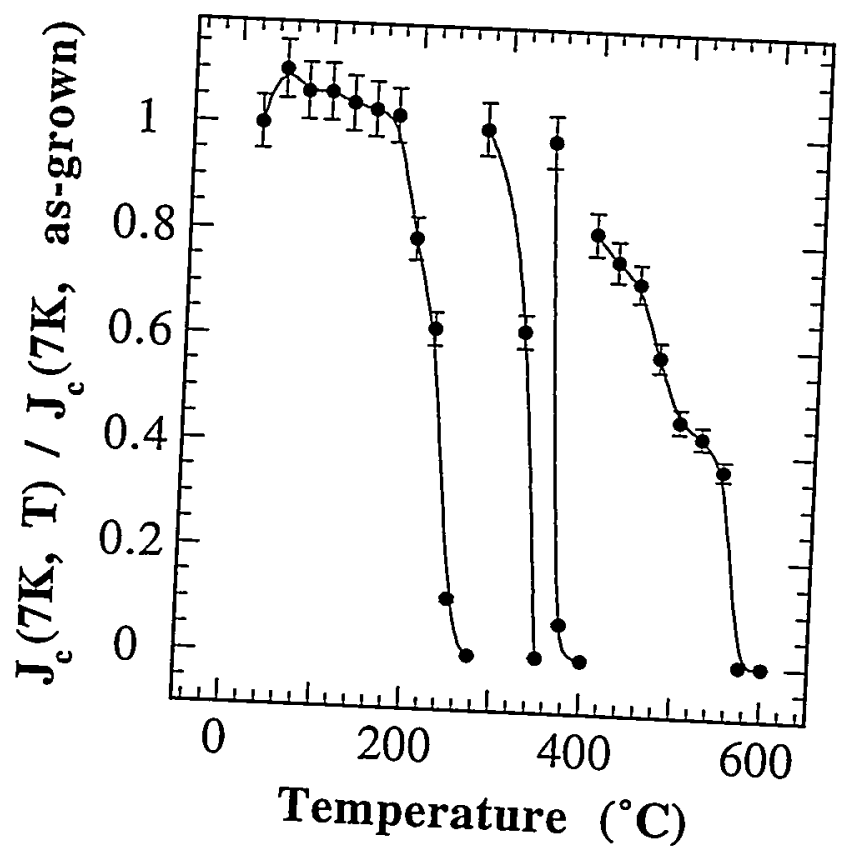

Fig. 8 


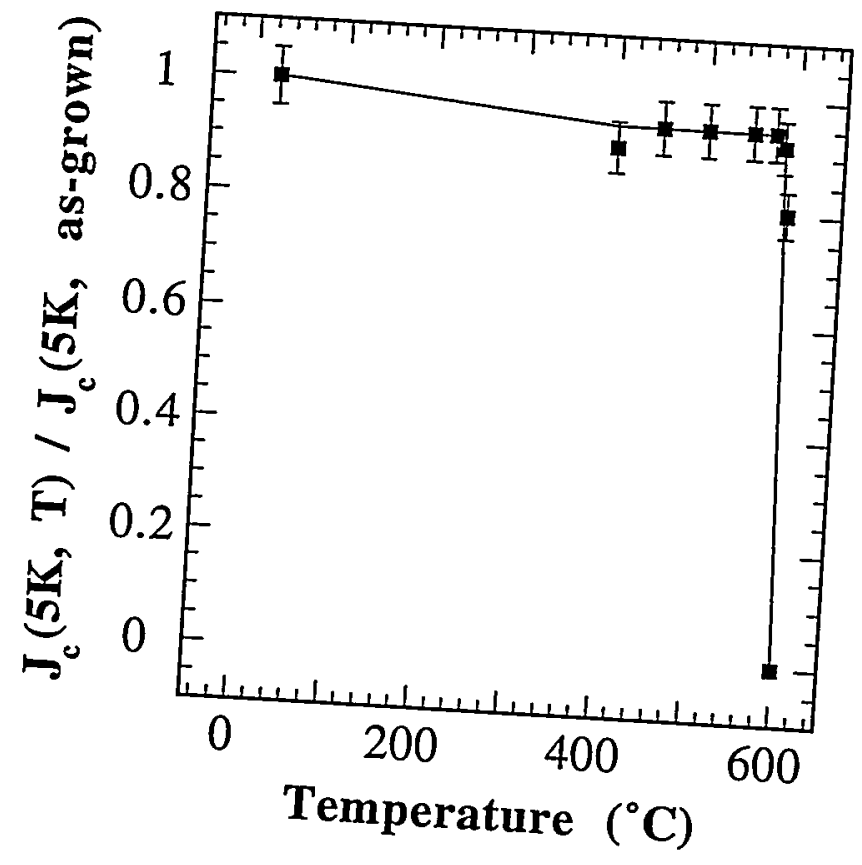

Fig. 9 